\title{
AVALIAÇÃO DOS EFEITOS DA TEMPERATURA NO RENDIMENTO E CARACTERIZAÇÃO FÍSICA DO BIO-ÓLEO PRODUZIDO A PARTIR DA PIRÓLISE DO BAGAÇO DE CANA
}

\author{
E. V. GONÇALVES ${ }^{1}$, F. L. SEIXAS ${ }^{1}$, M. H. N. O. SCALIANTE ${ }^{1}$, M. L. GIMENES $^{1 *}$ \\ ${ }^{1}$ Universidade Estadual de Maringá, Departamento de Engenharia Química \\ e-mail: marcelino@deq.uem.br
}

\begin{abstract}
RESUMO
Este trabalho examinou a produção de bio-óleo a partir da pirólise em reator batelada de leito fixo do bagaço de cana. Os experimentos foram conduzidos com a variação da temperatura final de processo de 400 a 600 ${ }^{0} \mathrm{C}$. Os resultados demonstraram que o rendimento dos produtos varia com a temperatura, sendo que a produção de líquido de pirólise aumenta com a elevação desta, atingindo seu máximo valor $(53,3 \%)$ a $600{ }^{\circ} \mathrm{C}$. A pesquisa também mostrou a importância da caracterização do bio-óleo para sua adequação a padrões e especificações do mercado. O líquido de pirólise apresentou como resultados teor de umidade de 17,32\%, pH de 2,34, densidade de $1,05 \mathrm{~g} / \mathrm{cm}^{3}$, viscosidades de 12,5 e $8,6 \mathrm{cP}$ (a 25 e $40{ }^{\circ} \mathrm{C}$ ), PCS de $17 \mathrm{MJ} / \mathrm{kg}$ e teor de cinzas de $0,04 \%$.
\end{abstract}

\section{INTRODUÇÃO}

As repetidas crises mundiais que alardeiam as nações, em sentido geral, estão ligadas à escassez de vários recursos, especialmente da água potável, de alimentos e de fontes de energia. A situação momentânea manifesta, sistematicamente, uma dependência massificada de fontes não renováveis de energia, sobretudo dos combustíveis fósseis. Daí a busca acentuada por opções energéticas que assumam não só o compromisso de não esgotamento de suas reservas, ou seja, fontes renováveis de energia; mas que, ao mesmo tempo, sejam economicamente praticáveis e respeitem esforços ligados à proteção ambiental.

Diante desse quadro, várias pesquisas têm buscado solucionar o problema energético, especialmente as que fazem uso da pirólise. Este tipo de processo consiste na decomposição termoquímica da biomassa em atmosfera inerte, resultando em 3 frações principais: líquido de pirólise, carvão que posteriormente pode ser queimado, ativado ou empregado em técnicas de melhoramento de solos (KUPPENS et al., 2014; MULLEN et al., 2010) e gases (óxidos de carbono, hidrogênio e hidrocarbonetos).

Inúmeras pesquisas realizadas ao longo dos últimos 30 anos descrevem o bio-óleo formado a partir da pirólise de biomassa como sendo um líquido marrom escuro (SEIXAS, 2014; MULLEN et al., 2010), com odor irritante (TSAI, LEE e CHANG, 2006; BRIDGWATER, 2012), com natureza química bastante complexa (contendo hidroxialdeídos, hidroxicetonas, açúcares, ácidos carboxílicos e compostos fenólicos) (WRIGHT et al., 2010) e com elevadíssimo teor de compostos oxigenados, o que reduz seu potencial energético. Por isso é 
importante ressaltar que tanto o rendimento quanto as características químicas e físicas do bio-óleo estão intimamente ligadas às variáveis de processo (umidade da biomassa, tamanho das partículas, pré-tratamento, configurações do reator, fornecimento de calor, transferência de calor, taxa de aquecimento, temperatura de reação e tempo de residência do vapor formado) (MOHAN, PITTMAN e STEELE, 2006).

Pelo fato de o processo de pirólise ocorrer a altas temperaturas e de maneira bastante rápida, o bio-óleo apresenta muita instabilidade físico-química, pois seu conteúdo está fora do estado de equilíbrio e apresenta espécies bastante reativas. Desse modo, para ser empregado como combustível líquido, o bio-óleo precisa romper uma série de barreiras técnicas e de mercado e se adequar a especificações e normas de qualidade (SOLANTAUSTA et al., 2011; GARCİA-PÈREZ, CHAALA e ROY, 2002) que estão diretamente relacionadas às suas características. As principais propriedades utilizadas para averiguar a estabilidade do bio-óleo são o pH, a viscosidade e o teor de água. Segundo Oasmaa e Peacocke (2001 apud Oasmaa et al., 2010) o teor de água do bio-óleo está intimamente ligado à densidade, à viscosidade e ao poder calorífico. A Tabela 1 evidencia os principais resultados da caracterização de bio-óleos advindos de diferentes condições de processo realizadas ao longo dos anos.

Tabela 1 - Propriedades comuns encontradas para bio-óleos derivados de madeira.

\begin{tabular}{lcc}
\hline \multirow{2}{*}{ Propriedade Física } & \multicolumn{2}{c}{ Valor Típico } \\
\cline { 2 - 3 } Teor de Umidade $(\%)$ & $15-30$ & 0,1 \\
$\mathrm{pH}$ & 2,5 & - \\
Densidade $\left(\mathrm{g} / \mathrm{cm}^{3}\right)$ & 1,20 & 0,94 \\
Viscosidade $\left(\mathrm{a} 500{ }^{0} \mathrm{C}\right)(\mathrm{cP})$ & $40-100$ & 180 \\
Poder Calorífico Superior $(\mathrm{MJ} / \mathrm{kg})$ & $16-19$ & 40 \\
Cinzas $(\%)$ & $0-0,2$ & 0,1
\end{tabular}

Fonte: Bridgwater (2003).
Inúmeras vantagens são relatadas por pesquisas que utilizam a pirólise da biomassa para a obtenção de energia e carvão. No que tange ao meio ambiente, é evidente que a disseminação do uso de combustíveis produzidos a partir da biomassa acarretará na diminuição da dependência de fontes não renováveis de energia; na neutralidade de dióxido de carbono emitido para a atmosfera durante a queima dos combustíveis, ocasionada por meio da incorporação do mesmo nos processos fotossintéticos das plantas; e na disposição final de resíduos de indústrias (madeira tratada), de colheitas (palhas especialmente) (BIBRZYCKI, KATELBACH-WOZNIAK e SZLEK, 2014) e de florestas (OASMAA et al., 2010), de lodo de esgoto (PARK et al., 2010), de estrume de porco (KUPPENS et al., 2014) e de algas (RIZZO et al., 2014), dentre tantos outros.

Contudo, diante do que foi exposto até o momento e contando que no ano de 2014 as usinas de açúcar e álcool conjuntamente ofertaram no mercado mais de 186 milhões de toneladas de bagaço de cana-de-açúcar (UDOP, 2015), este trabalho visa estudar a influência da variável temperatura no rendimento de bio-óleo obtido pelo processo de pirólise em reator de leito fixo e avaliar as propriedades físicas deste produto.

\section{EXPERIMENTOS}

\subsection{Preparação do Bagaço}

O bagaço cru foi gentilmente fornecido por uma usina da região com umidade de $24 \%$. O preparo do bagaço se deu mediante secagem em estufa com circulação de ar a 65 ${ }^{\circ} \mathrm{C}$ por $24 \mathrm{~h}$, trituração e peneiramento para a obtenção de partículas compreendidas entre 0,5 e $1,0 \mathrm{~mm}$.

A análise termogravimétrica foi realizada com o propósito de melhor entender o processo de degradação térmica do bagaço de cana. As amostras (10 mg) foram 
acondicionadas em cadinhos de platina e o experimento foi conduzido em um equipamento da marca Shimadzu TGA-50H, variando-se a temperatura de 25 a $900{ }^{\circ} \mathrm{C}$, à taxa de aquecimento de $10{ }^{\circ} \mathrm{C} / \mathrm{min}$ e com fluxo de $\mathrm{N}_{2}$ de $30 \mathrm{~mL} / \mathrm{min}$. Por fim, antes de seu uso, as seguintes propriedades da biomassa foram determinadas: teor de umidade (Norma 12/IV do Instituto Adolfo Lutz), teor de cinzas (Norma 12/IV do Instituto Adolfo Lutz), teor de material volátil (Norma E872-82 da ASTM) e teor de matéria fixa. De acordo com Debouldi et al. (2005 apud Omoniyi e Olorunnisola, 2014) esta última propriedade é obtida por diferença.

\subsection{Pirólise do Bagaço de Cana}

Para a produção do bio-óleo, o bagaço de cana tratado (aproximadamente 47,0 $\mathrm{g} \mathrm{em}$ batelada) foi pirolisado em um reator de leito fixo que está esquematizado na Figura 1. Além da variação da temperatura final nos patamares de $400,450,500,550$ e $600{ }^{\circ} \mathrm{C}$, as outras variáveis de processo (fixadas) foram: taxa de aquecimento de $10{ }^{\circ} \mathrm{C} / \mathrm{min}$; vazão de $\mathrm{N}_{2}$ de $200 \mathrm{ml} / \mathrm{min}$; a mistura gasosa que saía do reator era conduzida por um condensador de serpentina resfriado a $3,5{ }^{0} \mathrm{C}$; o produto líquido condensado foi coletado em um balão de fundo redondo mergulhado em banho de gelo mantido a $0{ }^{0} \mathrm{C}$. Os rendimentos tanto do líquido de pirólise quanto do carvão foram calculados pela divisão de sua massa final recuperada pelo montante de bagaço alimentado inicialmente. O rendimento do gás foi estimado como que para completar os $100 \%$ de massa inicial da biomassa.

\subsection{Caracterização do Bio-óleo}

Para a caracterização física do líquido de pirólise foram determinadas: a viscosidade, o $\mathrm{pH}$, o poder calorífico, o teor de água e o teor de cinzas.

$\mathrm{O}$ pH foi medido por meio de um pHmetro Digimed à temperatura ambiente de $20{ }^{0} \mathrm{C}$. O teor de água presente no bio-óleo foi obtido pelo método de Karl Fischer conduzido em um equipamento da marca OREON-AF8 e segundo a norma ASTM D1744. O teor de cinzas foi determinado segundo a norma 18/IV do Instituto Adolfo Lutz. O valor da viscosidade aparente foi determinado por meio de um reômetro rotacional modelo RVDV III ULTRA produzido pela empresa Brookfield Engineering Laboratories. Para esta determinação utilizou-se um sensor SP40, variou-se a taxa de deformação até $1650 \mathrm{~s}^{-1} \mathrm{e}$ mantiveram-se temperaturas constantes de 25 e $40{ }^{0} \mathrm{C}\left( \pm 2{ }^{0} \mathrm{C}\right)$. Já o PCS foi determinado por uma bomba calorimétrica da marca Parr 6200 .

Figura 1 - Desenho esquemático do Módulo Experimental de Pirólise.

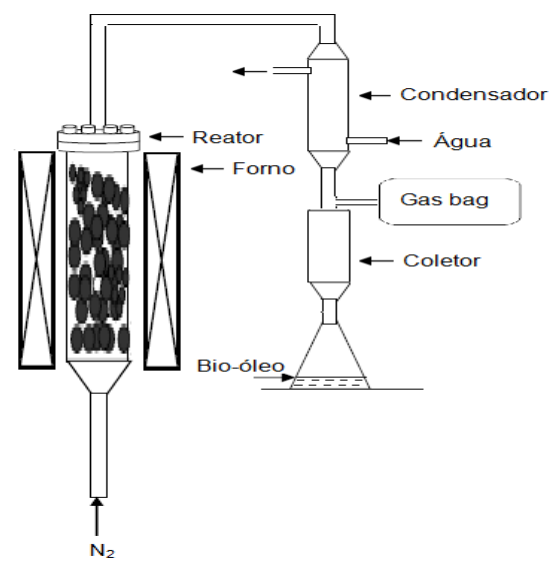

\section{RESULTADOS E DISCUSSÃO}

\subsection{Caracterização da Biomassa}

As propriedades físicas da biomassa estão apresentadas na Tabela 2.

O bagaço tratado mostrou $9,1 \%$ de umidade. Considerando que toda água presente no bagaço faça parte da composição final do bio-óleo, este resultado é condizente com o fato de que para se obter um bio-óleo estável e com uma única fase homogênea é necessário o emprego de uma biomassa com teor de umidade menor que $10 \%$ (LEHTO et al., 2010. De acordo com Asadullah et al. 
(2007), maiores teores de água na biomassa geradora resultam em maiores porcentagens de água no bio-óleo, diminuindo dessa forma, o poder de combustão e o $\mathrm{pH}$ deste (TSAI, LEE e CHANG, 2006).

Tabela 2 - Resultados da Caracterização do Bagaço de Cana.

\begin{tabular}{lc}
\hline Propriedade & Valor \\
\hline Teor de Umidade $(\%)$ & $9,099 \pm 0,406$ \\
Tamanho de Partícula $(\mathrm{mm})$ & $0,5-1,0$ \\
Densidade Aparente $\left(\mathrm{g} / \mathrm{cm}^{3}\right)$ & $0,10 \pm 0,001$ \\
Poder Calorífico Superior $(\mathrm{MJ} / \mathrm{kg})$ & 16,72 \\
Análise Centesimal & \\
Fração Volátil $(\%)$ & $76,586 \pm 1,322$ \\
Carbono Fixo $(\%)$ & $10,460 \pm 2,277$ \\
Cinzas $(\%)$ & $3,855 \pm 1,809$
\end{tabular}

A Tabela 2 mostra que o bagaço foi moído e peneirado para a obtenção de partículas entre 0,5 a $1,0 \mathrm{~mm}$. A necessidade de altas taxas de aquecimento e de transferência de calor, normalmente exige a alimentação de biomassa finamente moída (< $1 \mathrm{~mm}$ ) para a maximização do rendimento em bio-óleo (TSAI, LEE e CHANG, 2006; RADLEIN E QUIGNARD, 2013).

A determinação tanto da densidade aparente como do poder calorífico da biomassa são importantes, pois é por meio destes valores que é possível a comparação das densidades energéticas do bagaço e do líquido de pirólise. Para o caso em estudo foi constatado um valor de PCS de $16,72 \mathrm{MJ} / \mathrm{kg}$ e uma densidade aparente de $0,10 \mathrm{~g} / \mathrm{cm}^{3}$ para $\mathrm{o}$ bagaço.

A análise centesimal do bagaço revelou valores de $76,6 \%$ para a fração volátil, $10,5 \%$ para fração de carbono fixo e 3,9\% para o teor de cinzas. Isso está de acordo com o resultado encontrado pela Análise Termogravimétrica que está representada na Figura 2. Por esta figura é possível notar que a biomassa utilizada teve uma perda de massa de aproximadamente $10 \%$ para a temperatura de $100{ }^{0} \mathrm{C}$, provavelmente relacionada à evaporação da água contida no material, concordando com o resultado expresso $(9,1 \%)$ na Tabela 2. A análise termogravimétrica também evidenciou que a maior taxa de decomposição da biomassa (63\%) ocorreu entre as temperaturas de 250 e $350{ }^{0} \mathrm{C}$. Percebe-se que entre 350 e $420{ }^{0} \mathrm{C}$ houve outra fase de taxa de decomposição contínua com perda de massa de $11 \%$. Por fim, o restante do material $(13 \%)$ foi decomposto da temperatura de 420 a $490{ }^{\circ} \mathrm{C}$. A partir desta temperatura não houve mais perda de massa, indicando a presença de compostos inorgânicos na fração aproximada de $3 \%$, o que está coerente com o resultado obtido de $3,9 \%$ (Tabela 2). Todos estes resultados tendem a comprovar os estudos reportados por Yang et al. (2007), no qual é demonstrado que: a decomposição da hemicelulose acontece facilmente e ocorre principalmente na faixa de temperatura de 220 a $315{ }^{\circ} \mathrm{C}$; a degradação térmica da celulose ocorre principalmente em faixa de temperatura mais elevada que a hemicelulose $\left(315\right.$ a $\left.400{ }^{\circ} \mathrm{C}\right)$; a lignina é a estrutura de mais difícil decomposição, a qual normalmente ocorre de 150 até $900{ }^{\circ} \mathrm{C}$ e com menor taxa de perda de massa. Contudo, considerando que o material volátil é advindo principalmente da degradação térmica da hemicelulose e da celulose, a Figura 2 deixa claro que sua fração é de aproximadamente $74 \%$. Já, o restante do carbono que dá origem ao carvão e que é derivado principalmente da lignina, pode ser chamado de carbono fixo e, como visto na Figura 2, tem o valor aproximado de $13 \%$.

\subsection{Efeito da Temperatura de Pirólise}

Com a finalidade de se verificar a influência da variável temperatura, a pirólise do bagaço $(47 \mathrm{~g})$ foi conduzida à taxa de aquecimento de $10{ }^{\circ} \mathrm{C} / \mathrm{min}$, vazão de $\mathrm{N}_{2}$ de $200 \mathrm{ml} / \mathrm{min}$ e temperaturas finais de 400, 450, 500,550 e $600{ }^{\circ} \mathrm{C}$ com tempo de retenção de $1 \mathrm{~h}$ e $30 \mathrm{~min}$. Estes valores de temperaturas finais de processo foram escolhidos baseados no resultado expresso pela Análise 
Termogravimétrica, que demonstrou que a maior parte de material volátil fora decomposto principalmente a partir do patamar de $400{ }^{\circ} \mathrm{C}$.

Figura 2 - Análise Termogravimétrica do Bagaço de Cana

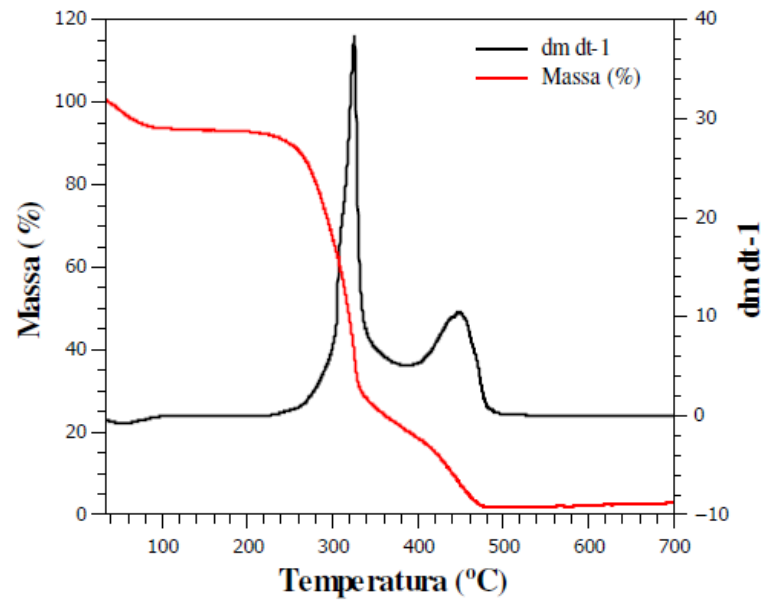

Os resultados apresentados na Figura 3 mostram que à menor temperatura $\left(400{ }^{\circ} \mathrm{C}\right) \mathrm{O}$ rendimento em bio-óleo também foi o menor; indicando concordância com o que foi apresentado pela Análise Termogravimétrica, pois neste caso boa parte da fração do material só pode ser volatilizada a temperaturas maiores que $420{ }^{0} \mathrm{C}$. Percebe-se com clareza que o aumento de rendimento em bio-óleo cresce com a elevação da temperatura até atingir nível máximo $(53,3 \%)$ a $600{ }^{\circ} \mathrm{C}$. Este comportamento é anormal, pois como afirma Bridgwater (2012) os resultados variam especialmente em decorrência da espécie de biomassa empregada e comumente o rendimento em líquido de pirólise apresenta nível máximo em torno de 480 a $520{ }^{\circ} \mathrm{C}$. A pesquisa de Islam, Islam e Islam (2003) mostrou que a variação do rendimento em bio-óleo de bagaço de cana também pirolisado em um reator de leito fixo possui um perfil parabólico voltado para baixo com a maior produção de líquido de pirólise (49\%) ocorrendo à temperatura de $450{ }^{\circ} \mathrm{C}$. O mesmo perfil parabólico foi relatado na pesquisa de Asadullah et al. (2007) onde o maior rendimento em bio-óleo $(66,1 \%)$ foi obtido à temperatura de $500{ }^{0} \mathrm{C}$. Desse modo, como ilustrado na Figura 3, o perfil ascendente do rendimento em bio-óleo até atingir $600{ }^{0} \mathrm{C}$ possui provável explicação baseada no fato de que os outros trabalhos mencionados envolveram taxas de aquecimento maiores (> $50{ }^{0} \mathrm{C} / \mathrm{min}$ ) do que a que foi utilizada neste estudo $\left(10^{0} \mathrm{C} / \mathrm{min}\right)$. No entanto, a causa deste fenômeno deve ser investigada com maior atenção e cuidado, pois outras variáveis de processo como as dimensões dos reatores, os tamanhos das partículas da biomassa, a vazão de $\mathrm{N}_{2}$ e o sistema de condensação e coleta também foram diferentes, podendo interferir diretamente nos resultados; e por isso serão alvos de análise em trabalhos futuros.

Figura 3 - Rendimento dos Produtos da Pirólise em Função da Temperatura Final de Processo.

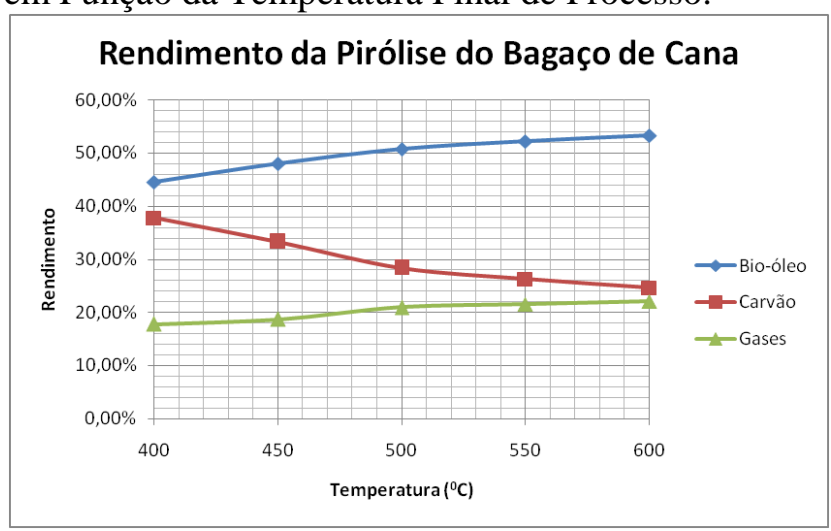

Também expresso na Figura 3, a produção tanto do carvão quanto do gás também varia com a temperatura. É possível notar que o rendimento em carvão reduz com o aumento da temperatura e possui seu maior valor $(37,8 \%)$ em $400{ }^{\circ} \mathrm{C}$. Em contrapartida os resultados expressos para o gás possuem comportamento oposto. Neste caso o menor rendimento $(17,7 \%)$ aconteceu a $400{ }^{0} \mathrm{C}$. Estes comportamentos podem ser explicados pelo fato da dificuldade, em temperaturas menores, da ocorrência de reações secundárias que transformem moléculas voláteis mais pesadas em gases mais leves e da decomposição térmica do carvão. 


\subsection{Características do Bio-óleo}

Para o uso do bio-óleo como combustível líquido aplicável a caldeiras, motores e turbinas há a necessidade do estabelecimento de padrões mínimos de qualidade relacionados principalmente a: estabilidade, homogeneidade, poder calorífico, $\mathrm{pH}$, viscosidade, densidade e conteúdo de cinzas (MOHAN, PITTMAN e STEELE, 2006). Seguindo este direcionamento, as características físicas do bio-óleo obtido na condição de melhor rendimento $\left(600{ }^{0} \mathrm{C}\right)$ estão resumidas na Tabela 3.

Tabela 3 - Resultados da Caracterização Física do Bio-óleo produzido a $600{ }^{\circ} \mathrm{C}$.

\begin{tabular}{lc}
\hline Propriedade Física & Valor \\
\hline Teor de Umidade $(\%)$ & 17,32 \\
$\mathrm{pH}\left(20{ }^{\circ} \mathrm{C}\right)$ & $2,34 \pm 0,02$ \\
Densidade $\left(20{ }^{\circ} \mathrm{C}\right)\left(\mathrm{g} / \mathrm{cm}^{3}\right)$ & $1,045 \pm 0,004$ \\
Viscosidade $\left(25\right.$ e $\left.40{ }^{\circ} \mathrm{C}\right)(\mathrm{cP})$ & 12,5 e 8,6 \\
Poder Calorífico Superior $(\mathrm{MJ} / \mathrm{kg})$ & 16,97 \\
Cinzas $(\%)$ & $0,0393 \pm 0,0681$
\end{tabular}

Segundo esta tabela o bio-óleo apresentou um teor de umidade de $17,32 \%$. Para Oasmaa e Peacocke (2001) o padrão de qualidade ideal para o uso do líquido de pirólise seria a apresentação de uma única fase e conseqüentemente um teor de água menor que $15 \%$. Diante deste fato $\mathrm{e}$ observando a Figura 4, é possível notar que o líquido de pirólise aparenta possuir uma fase orgânica mais escura (marrom) envolta numa fase aquosa mais clara (amarelada). $\mathrm{O}$ aspecto visual do bio-óleo demonstra a tendência do início da separação de fases que pode ser explicado pelo seu teor de água $(17,32 \%)$ maior que $15 \%$. Além disso, de acordo com Asadullah et al. (2007), maiores teores de água na biomassa geradora resultam em maiores porcentagens de água no bio-óleo, diminuindo dessa forma, o poder de combustão e o pH deste (TSAI, LEE e CHANG, 2006).
Diretamente relacionados ao teor de água estão o PCS, a densidade e a viscosidade. O bio-óleo produzido apresentou densidade de $1,05 \mathrm{~g} / \mathrm{cm}^{3}$, que é um valor maior do que da água. Esta condição permitiu ao líquido de pirólise possuir uma maior densidade energética. Desse modo foi constatado para o bio-óleo um PCS de 16,97 $\mathrm{MJ} / \mathrm{kg}$. Logo, em termos volumétricos, a densidade energética do líquido de pirólise, quando comparada à densidade energética do bagaço, expressa um valor aproximadamente 11 vezes maior. Isso justificaria a redução de custos com transporte caso o bio-óleo viesse a substituir ou concorrer com bagaço de cana no papel de matéria-prima para processos combustão, especialmente em motores estáticos (caldeiras, fornos, turbinas, entre outros).

Figura 4 - Aspecto Visual do Bio-óleo preparado a $600{ }^{\circ} \mathrm{C}$.

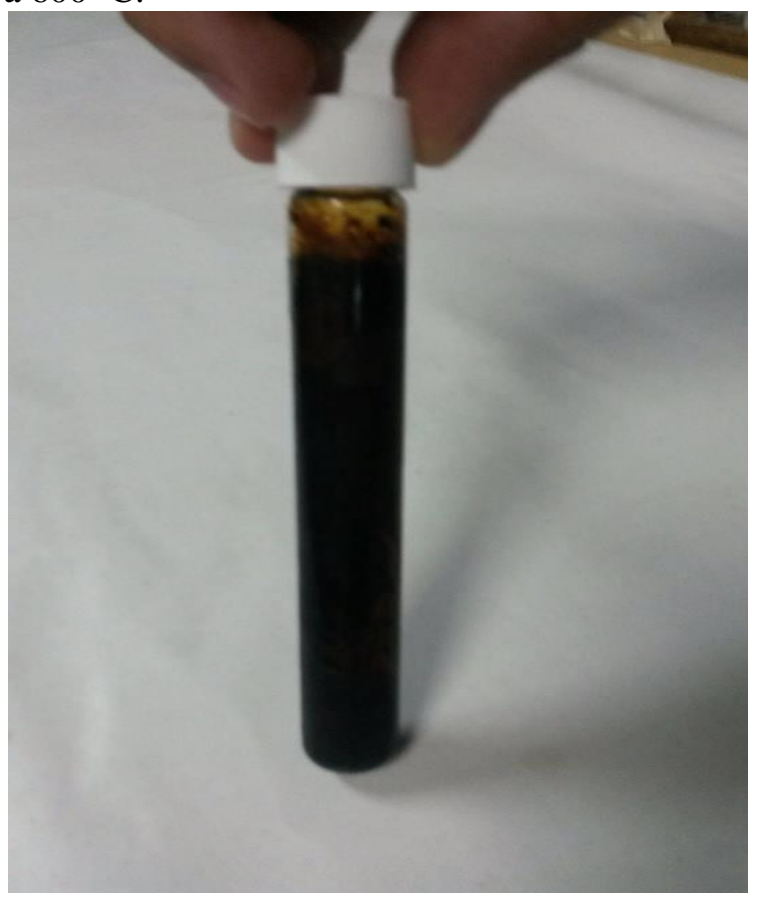

Os resultados mostrados na Tabela 3 para o valor da viscosidade $(12,5 \mathrm{cP}$ para 25 ${ }^{0} \mathrm{C}$ e $8,6 \mathrm{cP}$ para $40{ }^{0} \mathrm{C}$ ) foram determinados como sendo igual aos coeficientes angulares das retas ajustadas aos dados presentes na 
Figura 5 e são relativamente baixos quando comparados a outros trabalhos. Asadullah et al. (2007) obtiveram do bagaço de cana duas frações de bio-óleo (leve e média) que expressaram como viscosidade aparente, à temperatura de $20{ }^{0} \mathrm{C}, \quad 19,00$ e $4,25 \mathrm{cP}$ respectivamente. Por meio da Figura 5 é possível notar a existência de um comportamento aproximadamente linear entre a tensão de cisalhamento e a taxa de deformação, que é demonstrativo de característica de um fluido newtoniano. De acordo com Zhang, Shen e Liu (2007) a viscosidade de um líquido de pirólise reduz conforme maior for seu conteúdo de água e menor for o conteúdo de componentes insolúveis em sua fase aquosa. Segundo Bridgwater (2012) altos valores de viscosidade constantes nos líquidos de pirólise são responsáveis por: proporcionar grande queda de pressão nas tubulações, trazer dificuldade de atomização do bio-óleo para uso como combustível de transporte e aumentar os custos com equipamentos e bombas.

Figura 5 - Reogramas do Bio-óleo produzido a $600{ }^{\circ} \mathrm{C}$.

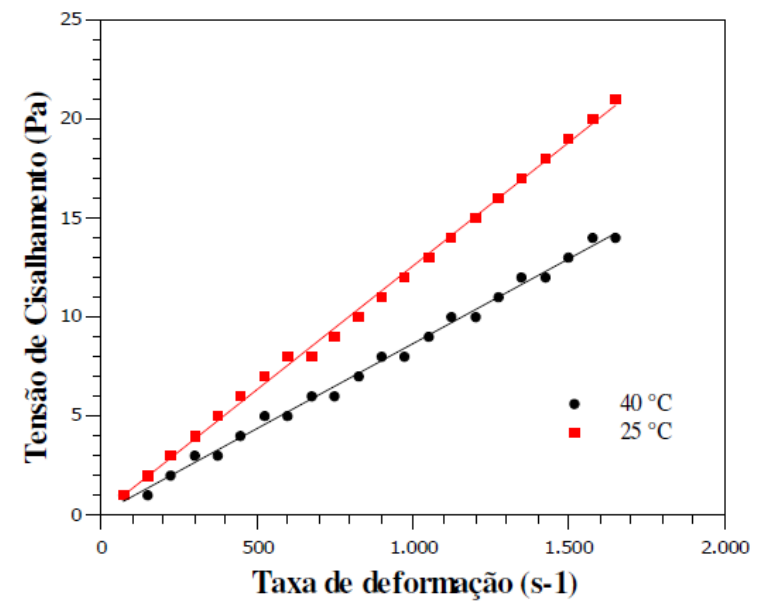

Por sua vez, o bio-óleo mostrou um caráter ácido e seu $\mathrm{pH}$ foi determinado na faixa de 2,34. Segundo Oasmaa, Elliot e Korhonen (2010) os ácidos carboxílicos, apesar de possuírem caráter fraco (baixo poder de dissolução em solução aquosa), são os principais causadores dos baixos valores encontrados para o $\mathrm{pH}$ dos líquidos de pirólise geralmente produzidos a partir das mais variadas fontes de biomassa. A pesquisa de Garcìa-Pèrez, Chaala e Roy (2002) obteve líquido da pirólise à vácuo de bagaço de cana com $\mathrm{pH}$ de 2,7. Contudo, o valor do $\mathrm{pH}$ do bio-óleo necessita ser finamente monitorado, pois como afirma Bridgwater (2012), pode causar corrosão e incrustações nos vasos, bombas e demais equipamentos a que forem submetidos.

Por fim, por sua natureza não menos importante, o teor de cinzas obtido para o líquido de pirólise em questão foi de $0,04 \%$. Cabe ressaltar a importância da determinação do teor de cinzas presente no bio-óleo, pois é um problema potencial o acúmulo dos resíduos e escórias deste, quando empregado em motores, turbinas e outros tipos de máquinas e equipamentos. A presença de cinzas no líquido de pirólise pode causar erosão, corrosão e incrustrações de tal maneira que para aplicações em turbinas seu limite superior permitido seria de $0,1 \%$ em massa (BOUCHER et al., 2000 apud GARCÌA-PÈREZ, CHAALA e ROY, 2002). Para Bridgwater (2012) os principais efeitos negativos da presença de cinzas no líquido de pirólise são: envelhecimento do óleo, sedimentação, entupimento de filtros, entupimento de catalisadores em processos de melhoramento, entupimento de injetores de motores à combustão e a aparição de metais alcalinos que catalisam reações secundárias indesejadas. Visto que os óleos combustíveis pesados praticados comercialmente expressam porcentagens de cinzas menores que $0,1 \%$ (CZERNICK e BRIDGWATER, 2004), o teor de cinzas encontrado neste trabalho evidencia um excelente resultado.

Contudo, de uma maneira geral, o bioóleo produzido atende à maioria das especificações técnicas reportadas pelo trabalho de Oasmaa e Peacocke (2001) sendo 
propício seu uso em caldeiras e motores a diesel.

\section{CONCLUSÕES}

Este trabalho estudou a produção de bio-óleo a partir da degradação térmica de bagaço de cana em um reator de leito fixo variando-se a temperatura de processo de 400 a $600{ }^{0} \mathrm{C}$. Os resultados constataram que o aumento da temperatura acarreta na elevação do rendimento em bio-óleo, o qual exibiu nível máximo de 53,3\% à temperatura de 600 ${ }^{0} \mathrm{C}$. Por fim, o conjunto de algumas das propriedades físicas do líquido de pirólise foi caracterizado, e em sua maioria, com exceção do teor de umidade, atenderam a uma série de exigências e especificações para que este possa apresentar qualidade suficiente para ser empregado como combustível líquido.

\section{NOMENCLATURA}

PCS - Poder Calorífico Superior

\section{REFERÊNCIAS}

ASADULLAH, M.; RAHMAN, M.A.; ALI, M.M.; RAHMAN, M.S.; MOTIN, M.A.; SULTAN, M.B.; ALAM, M.R.. Production of bio-oil from fixed bed pyrolysis of bagasse. Fuel,v.86, p.2514-2520, 2007.

ASTM International. Standard Test Method for Volatile Matter in the Analysis of Particulate Wood Fuels. E872-82 (Reapproved 2013).

BIBRZYCKI, Jakub; KATELBACHWOZNIAK, Anna; SZLEK, Andrzej. Investigation of biomass blending on pyrolysis process using TGA-FTIR technique.

CHEMICAL

ENGINEERING

TRANSACTIONS, v.37, 2014.
BRIDGWATER, A. V.. Renewable fuels and chemicals by thermal processing of biomass. Chemical Engineering Jornal, v.91, p. 87102, 2003.

BRIDGWATER, A. V.. Review of fast pyrolysis of biomass and product upgrading. Biomass and Bioenergy, v.38, p.68-94, 2012.

CZERNICK, S.; BRIDGWATER, A. V. Overview of Applications of Biomass Fast Pyrolysis Oil. Energy \& Fuels, v.18, p.590598, 2004.

GARCÌA-PEREZ, Manuel; CHAALA, Abdelkader; ROY, Christian. Vacuum pyrolysis of sugarcane bagasse. JOURNAL of ANALYTICAL and APPLIED PYROLYSIS, v.65, p.111-136, 2002.

INSTITUTO ADOLFO LUTZ. Normas Analíticas do Instituto Adolfo Lutz. v. 1: Métodos químicos e físicos para análise de alimentos, 3. ed. São Paulo: IMESP, 1985. p. 21-22.

INSTITUTO ADOLFO LUTZ. Normas Analíticas do Instituto Adolfo Lutz. v. 1: Métodos químicos e físicos para análise de alimentos, 3. ed. São Paulo: IMESP, 1985. p. 27-28.

ISLAM, Mohammad Rofiqul; ISLAM, Md. Nurul; ISLAM, Mohammad Nurul. FIXED BED PYROLYSIS OF SUGARCANE BAGASSE FOR LIQUID FUEL PRODUCTION. International Conference on Mechanical Engineering, Dhaka, Bangladesh, 2003.

KUPPENS, Tom; VAN DAEL, Miet; VANREPPELEN, Kenny; CARLEER, Robert; YPERMAN, Jan; SCHREURS, Sonja; VAN PASSEL, Steven. TechnoEconomic Assessment of Pyrolysis Char Production and Application - A Review. 
CHEMICAL

ENGINEERING

TRANSACTIONS, v.37, 2014.

LEHTO, Jani; OASMAA, Anja; SOLANTAUSTA, Yrjö; KYTÖ, Matti; CHIARAMONTI, David. Fuel oil quality and combustion of fast pyrolysis bio-oils. VTT TECHNOLOGY 87, Espoo, 2013.

MEIER, Dietrich; BELD, Bert van de; BRIDGWATER, Anthony V.; ELLIOT, Douglas C.; OASMAA, Anja; PRETO, Fernando. State-of-the-art of fast pyrolysis in IEA bioenergy member countries. Renewable and Sustainable Energy Reviews, v.20, p. 619-641, 2013.

MOHAN, Dinesh; Jr., Charles U. Pittman; STEELE, Philip H. Pyrolysis of Wood/Biomass for Bio-oil: A Critical Review. Energy \& Fuels, v.20, p. 848-889, 2006.

MULLEN, Charles A.; BOATENG, Akwasi A.; GOLDBERG, Neil M.; LIMA, Isabel M.; LAIRD, David A.; HICKS, Kevin B. Bio-oil and bio-char production from corn cobs and stover by fast pyrolysis. BIOMASS AND BIOENERGY,v. 34, p. 67-74, 2010.

OASMAA, Anja; ELLIOT, Douglas C.; KORHONEN, Jaana. Acidity of Biomass Fast Pyrolysis Bio-oils. Energy \& fuels, v.24, p. 6548-6554, 2010.

OASMAA, A.; SOLANTAUSTA, Y.; VESA, A.; KUOPPALA, E.; SIPILÄ, K.. Fast Pyrolysis Bio-Oils from Wood and Agricultural Residues. Energy \& Fuels, VOL. 24, p. 1380-1388, 2010.

OMONIYI, T. E.; OLORUNNISOLA A. O.. Experimental Characterisation of Bagasse Biomass Material for Energy Production. International Journal of Engineering and Technology, v.4, No. 10, 2014.
PARK, Hyun Ju; HEO, Hyeon Su; PARK, Young-Kwon; YIM, Jin-Heong; JEON, JongKi; PARK, Junhong; RYU, Changkook; KIM, Seung-Soo. Clean bio-oil production from fast pyrolysis of sewage sludge: Effects of reaction conditions and metal oxide catalysts. Bioresource Technology, v.101, p. S83-S85, 2010.

RADLEIN, D.; QUIGNARD, A.. A Short Historical Review of Fast Pyrolysis of Biomass. Oil \& Gas Science and Technology, v.68, p. 765-783, 2013.

RIZZO, Andrea Maria; BETTUCCI, Lorenzo; MARSILI-LIBELLI, Ilaria; CHIARAMONTI, David. Effect of Feedstock Composition on Quality, Yield and Properties of Pyrolisis Oil from Three Microalgae Species. CHEMICAL ENGINEERING TRANSACTIONS. v.37, 2014.

SEIXAS, Fernanda Lini. PRODUÇÃO DE CARVÃO ATIVADO DE BAGAÇO DE CANA-DE-AÇÚCAR E SUA APLICAÇÃO NA CLARIFICAÇÃO DA VINHAÇA. 2014. 175p. Tese (Doutorado em Engenharia Química) - Universidade Estadual de Maringá, Maringá, 2014.

SOLANTAUSTA, Y.; OASMAA, A.; SIPILÄ，K.; LINDFORS, C.; LEHTO, J.; AUTIO, J.; JOKELA, P.; ALIN, J.; HEISKANEN, J.. Bio-oil Production from Biomass: Steps toward Demonstration. Energy \& Fuels, v.26, p. 233-240, 2012.

TSAI, W.T.; LEE, M.K.; CHANG, Y.M. Fast pyrolysis of rice straw, sugarcane bagasse and coconut shell in an induction-heating reactor. JOURNAL OF ANALYTICAL AND APPLIED PYROLYSIS, v.76, p. 230-237, 2006.

UDOP. União dos Produtores de Bioenergia. Boletim de Conjuntura Energética. 
Disponível

em:

<http://www.udop.com.br/download/estatist ica/biomassa/2014_balanco_bagaco_cana_

uso_energetico.pdf $>$. Acesso em: 2 jun. de 2015.

WRIGHT, Mark M.; SATRIO, Justinus A.; BROWN Robert C.; DAUGAARD, Daren E.; HSU, David D. Techno-Economic Analysis of Biomass Fast Pyrolysis to Transportation Fuels. National Renewable Energy Laboratory, Golden, Colorado, USA, 2010.

YANG, Haiping; YAN, Rong; CHEN, Hanping; LEE, Dong Ho; ZHENG, Chuguang. Characteristics of hemicellulose, cellulose and lignin pyrolysis. Fuel, v.86, p. 1781-1788, 2007.

ZHANG, Le; SHEN, Chenjie; LIU, Ronghou. GC-MS and FT-IR analysis of the bio-oil with addition of ethyl acetate during storage. Frontiers in ENERGY RESEARCH, v.2, art. 3, 2014.

\section{AGRADECIMENTOS}

Agrademos ao Conselho Nacional de Pesquisa e Desenvolvimento (CNPq) pelo apoio financeiro, à Financiadora de Estudos e Projetos (FINEP) e ao Complexo de Centrais de Apoio à Pesquisa (COMCAP) pela estrutura concedida e à Usina de Açúcar e Álcool Santa Terezinha Ltda, localizada na cidade de Iguatemi-PR, pelo fornecimento do material (bagaço) utilizado na realização dos experimentos. 